\title{
RHEOLOGICAL PROPERTIES OF A COMMERCIAL FOOD GLAZE MATERIAL AND THEIR EFFECT ON THE FILM THICKNESS OBTAINED BY DIP COATING
}

\author{
B. E. MEZA, J. M. PERALTA, and S. E. ZORRILLA
}

Instituto de Desarrollo Tecnológico para la Industria Química (INTEC). Universidad Nacional del Litoral - CONICET. Güemes 3450, S3000GLN. Santa Fe. Argentina.

E-mail: bmeza@intec.unl.edu.ar

\begin{abstract}
Glazing refers to the application of a coating material onto the surface of foods to enhance their shine and appearance. The objective of this work was to analyze the rheological properties of a commercial food glaze material and to study their effect on the film thickness obtained by dip coating. Glazing suspension (83.33\% total solids content) was obtained using a commercial powder product. Apparent viscosity was determined (shear rate $0.6-50 \mathrm{~s}^{-1}$ ) and yield stress was estimated with a creep test (1-10 Pa during $5 \mathrm{~s}$ ). Experimental data were analyzed applying the generalized Herschel-Bulkley model. A comparison between average thickness values obtained by dip coating and using a phenomenological mathematical model was carried out. All determinations were done at 20,30, 40, and $50{ }^{\circ} \mathrm{C}$. Rheological parameters were obtained with satisfactory root mean squared errors. Good agreement between experimental and theoretical film thickness as affected by temperature was obtained.
\end{abstract}

\section{INTRODUCTION}

Glazing refers to the application of a coating glaze material onto the surface of foods to enhance their shine and appearance. Besides improving the aspect, glazing also contributes in extending the shelf life of foods, like in bakery and confectionery products (Chin et al., 2011). Many types of glaze materials can be used as film-forming fluids and can be made of proteinbased (milk, egg, etc.) and fat-based (shortening, vegetable oil, etc.) components. However, the main ingredient of a glazing suspension is usually table sugar (Nieto, 2009).

Rheological characterization is an important variable for coating technology (Chan and Venkatraman, 2006). Many physical phenomena that occur during coating of vertical surfaces, like draining and leveling, are influenced by rheological properties of the filmforming fluid. For this reason, the design of unit operations used in coating processes requires accurate data on the rheological properties of film-forming solutions and dispersions (Peressini et al., 2003). Specifically, in dip-coating technique, the quality of final film thickness was related to the viscosity and the yield stress of the film-forming fluid (Ghorbel $e t$ al., 2011).

In recent years, there have been little studies about glazing application on food products, although glazing is a common practice in baking and confectionery processes (Chin et al., 2011). However, the rheological characterization of food glaze materials was not found in literature. This information is useful to control and predict the film thickness during an 
industrial food glazing process. The objective of this work was to analyze the rheological properties of a commercial food glaze material and to study their effect on the film thickness obtained by dip coating. This study is necessary to complement previously published results related to mathematical modeling of the dip-coating process and its experimental validation (Peralta et al., $2014 \mathrm{a}, \mathrm{b}$ ).

\section{MATERIALS AND METHODS}

\subsection{Commercial Food Glaze Material}

A commercial food glaze powder was used (Ikebana Lheritier, San Carlos Centro, Santa Fe, Argentina). The product consisted in $95 \%$ icing sugar and 5\% vegetal protein. A glazing suspension was obtained dissolving $100 \mathrm{~g}$ of powder in $20 \mathrm{~mL}$ of tap water at $50{ }^{\circ} \mathrm{C}$ according to manufacturer recommendations. The final suspension $(83.33 \%$ total solids content $)$ was stored at $5^{\circ} \mathrm{C}$ during $24 \mathrm{~h}$ for further analysis. The composition of suspension supplied by the manufacturer was: $79.17 \%$ sucrose, $16.67 \%$ water, and $4.17 \%$ protein.

\subsection{Rheological Characterization}

Rheological measurements: Rheological measurements at 20,30,40, and $50 \pm 0.5{ }^{\circ} \mathrm{C}$ were done in triplicate using a stress controlled rheometer (RheoStress 80, Haake Inc. Instruments, Germany) with a plate-plate geometry (35 mm diameter and $1 \mathrm{~mm}$ gap). A thin film of silicone oil $(100 \mathrm{cP})$ was applied to the exposed sample edges to prevent water vaporization during measurements. Rotational rheometry was performed in the shear rate range of 0.6 to $50 \mathrm{~s}^{-1}$. Values of apparent viscosity as function of shear rate were determined. Creep tests were done applying a controlled stress during $5 \mathrm{~s}$ in the range of 1 to $10 \mathrm{~Pa}$. Values of strain as function of shear stress were obtained. Yield stress was estimated using the methodology proposed by Bhattacharya (1999). In the log-log plots of strain versus shear stress, the intersection between the two linear segments (obtained by linear regression) can give an estimation of yield stress for the studied condition.

Generalized Herschel-Bulkley model: Apparent viscosity as function of shear rate was analyzed applying the Generalized Herschel-Bulkley (GHB) model of four parameters proposed by Ofoli et al. (1987) for a generalized Newtonian fluid:

$$
\eta=\left(\tau_{0}^{m} \dot{\gamma}^{-m}+K^{m} \dot{\gamma}^{n-m}\right)^{1 / m}
$$

where $\eta$ is the apparent viscosity [Pa s], $\tau_{0}$ is the yield stress $[\mathrm{Pa}], \dot{\gamma}$ is the shear rate $\left[\mathrm{s}^{-1}\right]$, $K$ is the consistency index [Pa s$\left.{ }^{n / m}\right], n$ is the first behaviour index [-], and $m$ is the second behavior index [-]. This model was selected because is a generalized expression that includes other rheological models (Bingham, Casson, Heinz-Casson, Herschel-Bulkley, MizrahiBerk, Ostwald-de Waele, etc.) (Ofoli et al., 1987).

Temperature dependency of rheological parameters: The temperature dependency of $\tau_{0}$, $K$, and $n$ was analyzed using an Arrhenius type equation (Yang, 2001):

$$
A=A_{0} \exp \left[E_{A} /\left(R T^{*}\right)\right]
$$


where $A$ is the rheological parameter $\left(\tau_{0}, K\right.$, or $\left.n\right), A_{0}$ is an empirical constant, $T^{*}$ is the absolute temperature $[\mathrm{K}], E_{A}$ is the activation energy $\left[\mathrm{J} \mathrm{mol}^{-1}\right]$, and $R$ is the universal gas constant $\left[\mathrm{J} \mathrm{mol}^{-1} \mathrm{~K}^{-1}\right]$.

\subsection{Density}

Experimental density of glazing suspension at $20{ }^{\circ} \mathrm{C}$ was determined gravimetrically (10 replicates) weighing a recipient with known volume $\left(1.83 \mathrm{~cm}^{3}\right)$ and containing an aliquot of sample. The average density value obtained for these conditions was $1321 \pm 20 \mathrm{~kg} \mathrm{~m}^{-3}$. Theoretical density was estimated using the following expression (Michailidis et al., 2009):

$$
(1-\varepsilon) / \rho=\sum_{j=1}^{l}\left(x_{j} / \rho_{j}\right)
$$

where $\varepsilon$ is the porosity [-], $\rho$ is the food density $\left[\mathrm{kg} \mathrm{m}^{-3}\right], x_{j}$ is the weight fraction of each food component [-], and $\rho_{j}$ is the density of each food component [ $\left.\mathrm{kg} \mathrm{m}^{-3}\right]$. Values of $\rho_{j}$ were calculated with the following equation (Choi and Okos, 1986):

$$
\rho_{j}=a_{1}+a_{2} T+a_{3} T^{2}
$$

where $T$ is the temperature $\left(-40\right.$ to $\left.150{ }^{\circ} \mathrm{C}\right)$. For water $a_{1}=997.18, a_{2}=3.1439 \times 10^{-3}$, and $a_{3}=$ $-3.7874 \times 10^{-3}$; for protein $a_{1}=1330, a_{2}=-0.5184$, and $a_{3}=0$; while for carbohydrate $a_{1}=$ 1599.1, $a_{2}=-0.31046$, and $a_{3}=0$.

Porosity, considered as the air fraction within the glazing suspension, was estimated by images captured using an optical microscope (Olympus BH-2, Tokyo, Japan) (Figure 1). Air bubbles were identified and quantified, obtaining an estimated porosity value of 0.07 .
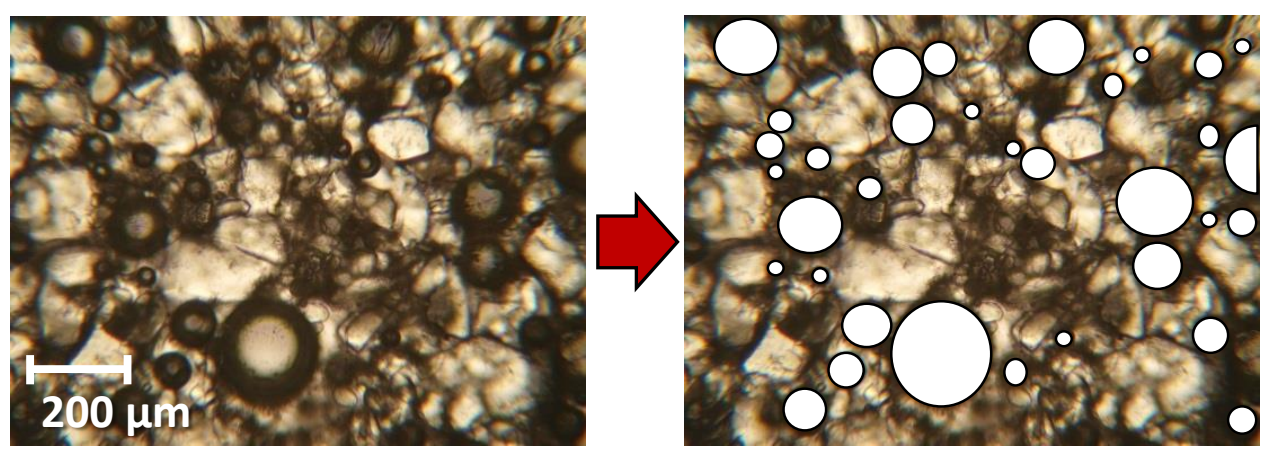

Figure 1 - Porosity estimation by optical microscopy.

\subsection{Average Film Thickness}

Experimental thickness: Experimental average film thickness values were obtained by quintuplicate using the dip-coating methodology proposed by Cisneros-Zevallos and Krochta (2003) with modifications. Glass plates ( $75 \mathrm{~mm}$ high, $25 \mathrm{~mm}$ width, and $1 \mathrm{~mm}$ thick) were used as substrate, where the total area available for coating was $20.8 \mathrm{~cm}^{2}$. Glazing suspension was conditioned at each temperature $\left(20,30,40\right.$, and $\left.50^{\circ} \mathrm{C}\right)$ using a termostatized bath with recirculation Haake DC 30/Haake W26 (Haake Inc. Instruments, Paramus, USA). During dip 
coating, the substrate was submerged during $10 \mathrm{~s}$ by hand in the glass vessel containing the suspension and then withdrawal quickly, draining the suspension over vessel during $30 \mathrm{~s}$. After that, each substrate was placed in plastic containers and sealed hermetically to prevent water vaporization. The film thickness of glazing suspension was determined using the following expression (Bhattacharya and Patel, 2007):

$$
\langle h\rangle_{\exp }=w /\left(\rho A_{T}\right)
$$

where $\langle h\rangle_{\exp }$ is the experimental average film thickness [m], w is the film weight [kg] and $A_{T}$ is the total area available for coating $\left[\mathrm{m}^{2}\right]$. Values of $w$ were determined by difference between the weight of substrate before and after dipping.

Theoretical thickness: Theoretical average film thickness values were estimated using the phenomenological mathematical model proposed by Peralta et al. (2014 a) for a dipcoating process of a plate during the draining stage based on Equation (1):

$$
\begin{aligned}
& \langle h\rangle={ }_{2} F_{1}\left[1,-\frac{2}{m} ; \frac{1}{n}+1 ; 1-S_{\tau_{0}}^{m}\right] h+\frac{n h}{m(n+1)}\left(1-S_{\tau_{0}}^{m}\right)_{2} F_{1}\left[1,1-\frac{2}{m} ; \frac{1}{n}+2 ; 1-S_{\tau_{0}}^{m}\right] \\
& \left(\rho g_{x} h / K\right)^{m}-\left(\tau_{0} / K\right)^{m}-[x /(h t)]^{n}=0
\end{aligned}
$$

where $\langle h\rangle$ is the theoretical average film thickness [m], $h$ is the film thickness at the $x$ position of the plate $[\mathrm{m}], g_{x}$ is the gravity acceleration $\left[\mathrm{m} \mathrm{s}^{2}\right],{ }_{2} F_{1}[a, b ; c ; z]$ is the Gauss hypergeometric function, $S_{\tau_{0}}=\tau_{0} /\left(\rho g_{x} h\right)$, and $t$ is time [s].

\subsection{Statistical Analysis}

Parameters obtained from Equations (1) and (2) were determined using nonlinear and linear regression, respectively. ANOVA was used and, when the effect of the factors was significant $(P<0.05)$, the Tukey's honestly significant difference multiple ranks test was applied (confidence level 95\%). In addition, root mean square errors (RMSE) were calculated:

$$
R M S E=\sqrt{N^{-1} \sum_{i=1}^{p}\left(\langle h\rangle_{\exp }-\langle h\rangle\right)^{2}}
$$

All the statistical analysis was performed using Minitab 13.20 (Minitab Inc., State College, PA).

\section{RESULTS AND DISCUSSION}

\subsection{Rheological Behavior}

Values of apparent viscosity as function of shear rate for the glazing suspension are shown in Figure 2. The shape of flow curves indicates a shear-thinning behavior, where apparent viscosity decreases as shear rate increases at all temperatures. According to Rao (1999), shear-thinning may occur because the breakdown of structural units in a food due to the hydrodynamic forces generated during shear. Taking into account the composition, the analyzed glazing suspension has high sucrose content (approximately 80\%). Quintas et al. 
(2006) have reported that saturated sucrose solutions, with concentrations higher than $60 \%$, presented Newtonian behavior in a wide range of temperatures. However, those authors have noticed a deviation from Newtonian behavior at some critical values of temperature and concentration of saturated sucrose solutions, probably due to changes in the sample structure, such as crystal nucleation.

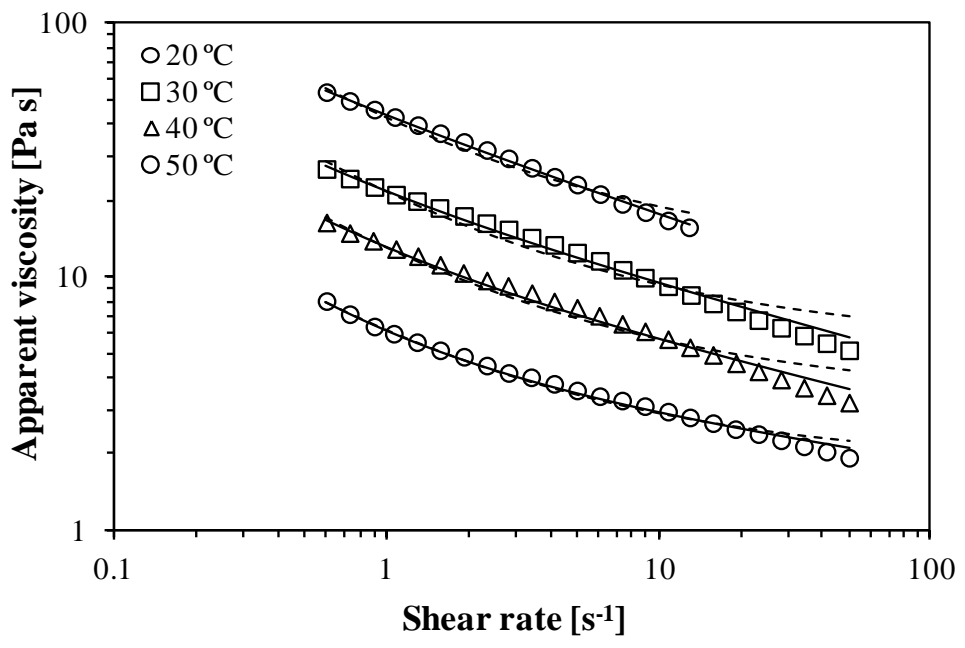

Figure 2 - Apparent viscosity as function of shear rate for a commercial food glaze material.

Symbols are experimental values (one of tree replicates). Solid line represents case 1

(Herschel-Bulkley) and dash lines represent case 2 (Casson) of the GHB model.

Values of GHB model for the glazing suspension are shown in Table 1. Two particular cases were considered: (1) Herschel-Bulkley ( $m=1$ and $\left.\tau_{0} \neq 0\right)$ and (2) Casson $(n=m=1 / 2)$. Yield stress values exhibited in case 1 were estimated by creep test and yield stress values presented in case 2 were obtained by regression. Values of $R M S E$ obtained for Herschel-Bulkley case were lower than values obtained for Casson case, indicating a better agreement between experimental and theoretical data for all temperatures (Figure 2).

Table 1 - Values of GHB model (Equation (1)) of a commercial food glaze material.

\begin{tabular}{ccccccc}
\hline Case & $\mathrm{T}\left[{ }^{\circ} \mathrm{C}\right]$ & $\tau_{0}{ }^{+}[\mathrm{Pa}]$ & $K^{+}\left[\mathrm{Pa} \mathrm{s}^{n / m}\right]$ & $n^{+}[-]$ & $m[-]$ & $R M S E[\mathrm{~Pa} \mathrm{~s}]$ \\
\hline$(1) m=1 ;$ & 20 & $4.46 \pm 0.21^{\mathrm{c}^{*}}$ & $38.0 \pm 1.1^{\mathrm{d}}$ & $0.64 \pm 0.03^{\mathrm{a}}$ & 1 & 0.48 \\
$\tau_{0} \neq 0$ & 30 & $4.18 \pm 0.24^{\mathrm{c}^{*}}$ & $16.5 \pm 1.1^{\mathrm{c}}$ & $0.72 \pm 0.02^{\mathrm{b}}$ & 1 & 0.58 \\
(Herschel- & 40 & $3.46 \pm 0.63^{\mathrm{b}^{*}}$ & $9.70 \pm 0.23^{\mathrm{b}}$ & $0.74 \pm 0.01^{\mathrm{c}}$ & 1 & 0.22 \\
Bulkley) & 50 & $2.22 \pm 0.64^{\mathrm{a}^{*}}$ & $4.22 \pm 0.46^{\mathrm{a}}$ & $0.82 \pm 0.02^{\mathrm{d}}$ & 1 & 0.08 \\
\hline \multirow{2}{*}{$(2) m=n=1 / 2$} & 20 & $10.3 \pm 1.2^{\mathrm{d}}$ & $10.7 \pm 1.0^{\mathrm{d}}$ & $1 / 2$ & $1 / 2$ & 1.43 \\
$($ Casson) & 30 & $5.02 \pm 0.59^{\mathrm{c}}$ & $5.25 \pm 0.23^{\mathrm{c}}$ & $1 / 2$ & $1 / 2$ & 1.16 \\
& 40 & $3.39 \pm 0.15^{\mathrm{b}}$ & $3.16 \pm 0.10^{\mathrm{b}}$ & $1 / 2$ & $1 / 2$ & 0.51 \\
& 50 & $1.40 \pm 0.13^{\mathrm{a}}$ & $1.84 \pm 0.10^{\mathrm{a}}$ & $1 / 2$ & $1 / 2$ & 0.13 \\
\hline
\end{tabular}

${ }^{+}$Mean values and standard deviations of three replicates. ${ }^{*}$ Estimated by creep test. ${ }^{\text {a-d }}$ Means within a column with different letters are significantly different $(P<0.05)$ within each case.

Yield stress values decrease as temperature increases (Table 1). Because yield stress is related to the strength of the network structure, when this value is exceeded during the condition of experimentation, the fluid flows like a truly viscous material with finite viscosity 
(Nguyen and Boger, 1992). Similarly, consistency index values decrease as temperature increases, the trend of apparent viscosity (Figure 2) being similar to $K$ for all temperatures. This behavior is expected because $K$ can also be defined as the apparent viscosity of a power law fluid at a shear rate of $1 \mathrm{~s}^{-1}$ (Rao, 1999). On the other hand, flow behavior indexes increase as temperature increases, indicating that the rheological behavior of glazing suspension tends to be closer to Newtonian flow at higher temperatures.

\subsection{Experimental and Theoretical Film Thickness}

A comparison between experimental and theoretical average film thickness obtained by dip coating at 20,30, 40, and $50^{\circ} \mathrm{C}$ is shown in Figure 3. Significant difference among experimental values was observed, showing that film thickness decreases as temperature increases. Theoretical data were obtained using Equations (6) and (7) with experimental yield stress values obtained by creep test, rheological parameters ( $K$ and $n$ ) obtained for the particular case 1 (Table 1), and experimental density value (Section 2.3). A satisfactory agreement between experimental and theoretical data was obtained (Figure 3). Similar results were observed by Peralta et al. (2014 b), who reported good theoretical predictions with the phenomenological mathematical model used in the present work. Authors estimated the theoretical average film thickness for a dip-coating process of a plate during the draining stage using the rheological parameters of the GHB model obtained from literature for milk chocolate and deep-fat frying batters (Lee et al., 2002; Karnjanolarn and McCarthy, 2006).

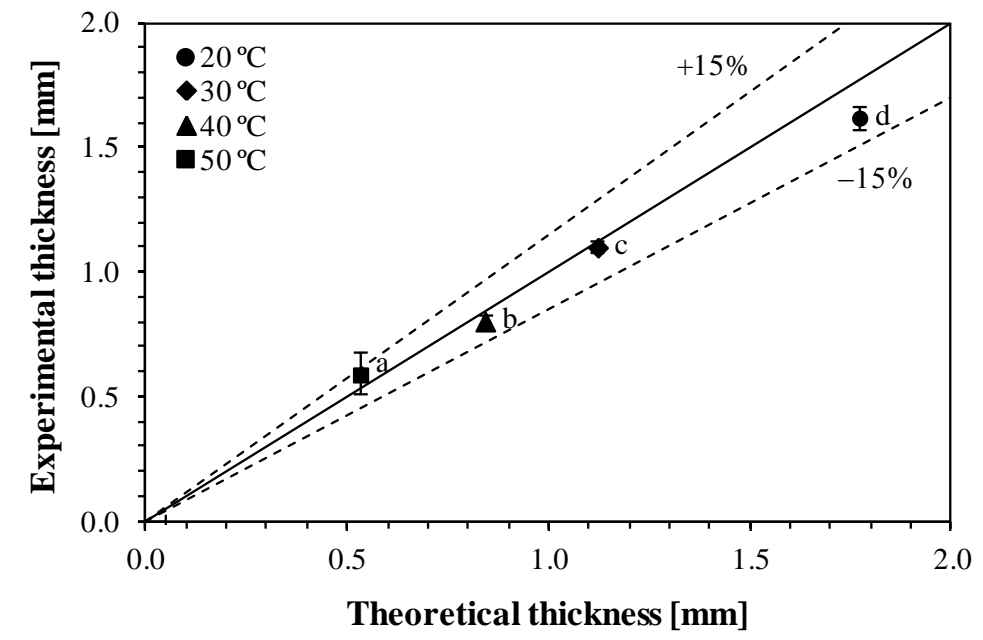

Figure 3 - Experimental and theoretical average film thickness values obtained for a commercial food glaze material. Bars are standard deviations and lines represent $\pm 15 \%$ error.

Means with different letters are significantly different $(P<0.05)$.

A comparison between experimental and theoretical average film thickness obtained by dip coating in the range of 15 to $55^{\circ} \mathrm{C}$ is shown in Figure 4. In this case, theoretical data were obtained using Equations (6) and (7) but considering the temperature dependency of rheological parameters and density. From this dependence, activation energies evaluated by linear regression analysis of data (Equation (2)) were 1905, 59445, and $6613 \mathrm{~J} \mathrm{~mol}^{-1}$ for $\tau_{0}$, $K$, and $n$, respectively. In all cases a good adjustment was obtained $\left(R^{2}>0.86\right)$. Moreover, theoretical density values at each temperature were calculated using Equation (4). As example, the theoretical value obtained at $20{ }^{\circ} \mathrm{C}$ was $1336 \mathrm{~kg} \mathrm{~m}^{-3}$, being similar to the 
experimental density value obtained at the same temperature $\left(1321 \mathrm{~kg} \mathrm{~m}^{-3}\right)$. A satisfactory prediction of average film thickness was obtained in the range of temperatures of 15 to $55^{\circ} \mathrm{C}$ (Figure 4).

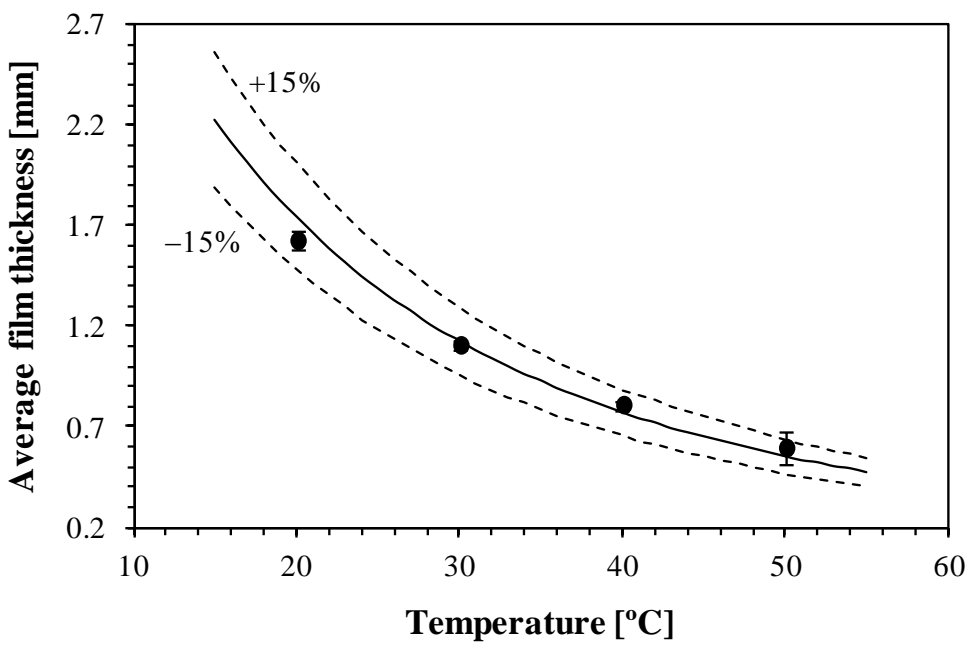

Figure 4 - Average film thickness obtained for a commercial food glaze material. Symbols are experimental data and bars represent standard deviations. Solid line represents theoretical data and dash lines represent $\pm 15 \%$ error.

\section{CONCLUSIONS}

The commercial food glaze material can be analyzed as a generalized Newtonian fluid. A shear thinning behavior was observed for all studied temperatures. Experimental yield stress values and rheological parameters were obtained ( $\tau_{0}$ and $K$ decrease while $n$ increases as temperature increases) and used to predict theoretical average film thickness. A satisfactory agreement between experimental and theoretical values was obtained for all temperatures. As consequence, rheological properties of the analyzed commercial food glaze material depend on temperature and influence the average film thickness obtained by dip coating. This information can be useful to control and predict the film thickness during an industrial food glazing process.

\section{REFERENCES}

BHATTACHARYA, S. Yield stress and time-dependent rheological properties of mango pulp. J. Food Sci., v. 64, p. 1029-1033, 1999.

BHATTACHARYA, S.; PATEL, B. K. Simulation of coating process: rheological approach in combination with artificial neural network. J. Texture Stud., v. 38, p. 555-576, 2007.

CHAN, C-M.; VENKATRAMAN, S. Coating Rheology. In Coatings Technology Handbook, A. A. Tracton (Ed.). Boca Raton: CRC Taylor \& Francis, 2006.

CHIN, N. L.; ABDULLAH, R.; YUSOF, Y. A. Glazing effects on bread crust and crumb staling during storage. J. Texture Stud., v. 42, p. 459-467, 2011.

CHOI, Y.; OKOS, M. R. Food Engineering and Process Applications. London: Elsevier Applied Science, 1986. 
CISNEROS-ZEVALlOS, L.; KROCHTA, J. M. Dependence of coating thickness on viscosity of coating solution applied to fruits and vegetables by dipping method. J. Food Sci., v. 68, p. 503-510, 2003.

GHORBEL, D.; BARBOUCHE, A.; RIAHI, H.; BRAHAM, A.; ATTIA, H. Influence of fat content on rheological properties of molten ice cream compound coatings and thickness of solidified products. J. Food Process Eng., v. 34, p. 144-159, 2011.

KARNJANOLARN, R.; MCCARTHY, K. L. Rheology of different formulations of milk chocolate and the effect on coating thickness. J. Texture Stud., v. 37, p. 668-680, 2006.

LEE, S.; NG, P. K. W.; STEFFE, J. F. Effects of controlled mixing on the rheological properties of deep-fat frying batters at different percent solids. J. Process Eng., v. 25, p. 381-394, 2002.

MICHAILIDIS, P. A.; KROKIDA, M. K.; RAHMAN, M. S. Data and models of density, shrinkage and porosity. In Food Properties Handbook, M. S. Rahman, (Ed.). Boca Raton: CRC Press, 2009.

NGUYEN, Q. D.; BOGER, D. V. Measuring the flow properties of yield stress fluids. Annual Rev. Fluid Mech., v. 24, p. 47-88, 1992.

NIETO, M. B. Structure and function of polysaccharide gum-based edible films and coatings. In Edible Films and Coatings for Food Applications. M. E. Embuscado, K. C.; Huber (Eds.). New York: Springer Science+Business Media, 2009.

OFOLI, R.Y.; MORGAN, R. G.; STEFFE, J. F. A generalized rheological model for inelastic fluid foods. J. Texture Stud., v. 18, p. 213-230, 1987.

PERALTA, J. M.; MEZA, B. E.; ZORRILLA, S. E. Mathematical modeling of dip-coating process using a generalized Newtonian fluid. 1. Model development. Ind. Eng. Chem. Res., v. 53, p. 6521-6532, 2014 a.

PERALTA, J. M.; MEZA, B. E.; ZORRILLA, S. E. Mathematical modeling of dip-coating process using a generalized Newtonian fluid. 2. Model validation and sensitivity analysis. Ind. Eng. Chem. Res., v. 53, p. 6533-6543, 2014 b.

PERESSINI, D.; BRAVIN, B.; LAPASIN, R.; RIZZOTTI, C.; SENSIDONI, A. Starchmethylcellulose based edible films: rheological properties of film-forming dispersions. J. Food Eng., v. 59, p. 25-32, 2003.

QUINTAS, M.; BRANDAO, T. R. S.; SILVA, C. L. M.; CUNHA, R. L. Rheology of supersaturated sucrose solutions. J. Food Eng., v. 77, p. 844-852, 2006.

RAO, M. A. Rheology of Fluid and Semisolid Foods: Principles and Applications. New York: Springer Science+Business Media LLC, 2007.

YANG, M-H. The rheological behavior of polyacrylamide solution II. Yield stress. Polymer Testing, v. 20, p. 635-642, 2001.

\section{Acknowledgments}

This research was supported partially by Universidad Nacional del Litoral (Santa Fe, Argentina), Consejo Nacional de Investigaciones Científicas y Técnicas (CONICET), and Agencia Nacional de Promoción Científica y Tecnológica (ANPCyT). 